Bol. Acad. peru. leng. 65. 2019 (51-71)

\title{
LA (IN)TRASCENDENCIA DEL AMOR: UN ANÁLISIS DE LA TELESERIE QUÉ VIDA MÁS TRISTE
}

\section{THE (IN) TRASCENDENCE OF LOVE: AN ANALYSIS OF THE TELESERIE WHAT $A$ SAD LIFE}

\author{
Álvaro Domingo Acevedo Zárate \\ Universidad Peruana de Ciencias Aplicadas
}

$$
\begin{aligned}
& \text { Para Ariel, } \\
& \text { el grande }
\end{aligned}
$$

\section{Resumen:}

Esta investigación tiene por objetivo indagar acerca de cuál es la función que se le atribuye al amor en la construcción de la identidad de un sujeto cínico a través del análisis del diálogo y el lenguaje corporal. Para ello, se analiza la serie española Qué vida más triste, producción audiovisual que se transmitió, primero, por la plataforma de videos YouTube y, luego, por televisión entre los años 2005 y 2010. Esta serie es analizada a la luz de los planteamientos filosóficos de Peter Sloterdijk, Alain Badiou y Slavoj Žižek, así como la teoría psicoanalítica de Jacques Lacan. Las conclusiones a las que se llegan nos muestran que la serie plantea que el sujeto cínico, para serlo, debe renunciar a un encuentro «real» con el otro, dado que vive ensimismado en la búsqueda de su propio goce y ve a las demás personas como meros instrumentos. Sin embargo, la serie también 
plantea que hay una manera de romper con el aislamiento del sujeto cínico: el amor. Pero un amor vivido como lo que el filósofo francés Alain Badiou llama «un proceso de verdad», pues si se vive de otra manera, el amor pierde toda su potencia liberadora y se convierte en un mero simulacro que no hace sino reafirmar al sujeto en su cinismo y, por ende, en su aislamiento.

\section{Abstract:}

This research aims to inquire about the role attributed to love in the construction of the identity of a cynical subject through the analysis of dialogue and body language. For this, the Spanish series What a sad life is analyzed, an audiovisual production that was transmitted, first, by the YouTube video platform and then by television between 2005 and 2010. This series is analyzed in the light of the philosophical approaches of Peter Sloterdijk, Alain Badiou and Slavoj Žižek, as well as the psychoanalytic theory of Jacques Lacan. The conclusions that are reached show us that the series states that the cynical subject, to be one, must give up a «real» encounter with the other, since he lives in self-absorption in search of his own enjoyment and he sees other people as mere instruments. However, the series also states that there is a way to break the isolation of the cynical subject: love. But a love lived as what the French philosopher Alain Badiou calls «a process of truth», because if it is lived differently, love loses all its liberating power and becomes a mere simulation that only reaffirms the subject in his cynicism and, therefore, in his isolation.

Palabras clave: cinismo, amor, psicoanálisis, lenguaje, cuerpo.

Key words: cynicism, love, psychoanalysis, language, body.

Fecha de recepción:

$28 / 03 / 2019$

Fecha de aceptación:

$31 / 05 / 2019$ 


\section{Introducción}

Qué vida más triste (en adelante, QVMT) fue una serie española que se transmitió por internet, primero, y por televisión, después, en el lapso que va de los años 2005 al 2010. Fue creada, escrita y dirigida por Rubén Ontiveros, y protagonizada por Borja Pérez y Joseba Caballero.

La serie narra la historia de Borja Pérez, un gruista de 30 años de edad, que vive en la ciudad de Basauri (localidad de Vizcaya, País Vasco, España). "Borja representa un poco de todos nosotros, es un perdedor al uso, con el que todos en algún momento nos podemos sentir identificados», dice Rubén Ontiveros en una entrevista al portal Ionlitio. Así pues, este «perdedor al uso» divide su tiempo libre entre su novia, Nuria Herrera, y su mejor amigo, Joseba Caballero (a estos personajes, habría que agregar al propio Rubén Ontiveros, quien, dentro de la serie, es presentado como un amigo más de Borja, aunque con el tiempo va cobrando más importancia). A lo largo de la serie transitarán otros personajes, algunos con más protagonismo que otros, pero serán estos cuatro los que se mantendrán constantes en todas las temporadas.

El objetivo del presente trabajo es visibilizar, a través del análisis del diálogo y el lenguaje corporal, las distintas maneras en que la serie presenta al protagonista como un sujeto desprotegido e impotente frente al cinismo contemporáneo, que lo aprisiona y asfixia. No obstante, también se visibiliza la trascendencia del amor como vía para evitar el extravío del sujeto en el cinismo.

Para poder comenzar el análisis, este trabajo parte de una breve introducción a la serie. Posteriormente, se aborda el análisis de la serie a partir de los planteamientos que los filósofos como Peter Sloterdijk y Slavoj Žižek han hecho sobre el cinismo, prestando especial atención al segundo por el uso que hace del psicoanálisis lacaniano, ya que esta es una herramienta teórica muy útil para comprender la situación y las posibilidades del sujeto frente al cinismo contemporáneo. Finalmente, se discute el papel que se le otorga al amor en la serie; para ello, me sirvo de las ideas del filósofo Alain Badiou. 


\section{Los diálogos en Qué vida más triste}

Según ha manifestado el creador de QVMT, la serie nació con la intención de «mostrar las reflexiones [de] un domingo [...] de resaca de alguien [...] normal» (Ionlitio, 2011), siguiendo el modelo de los miles de videoblogs que se encuentran en internet, en los que usuarios de todas partes del mundo se sientan frente a una cámara a contar lo que les ha sucedido recientemente para luego publicar estos videos en algún portal, en donde podrán ser vistos por quien así lo desee. Por esta razón, desde los primeros capítulos de la primera temporada, QVMT se planteó como un «relato verídico», es decir, una especie de diario personal en el que el protagonista publicaba, cada domingo, un breve video (de alrededor de tres minutos o menos) en el que narraba o reflexionaba acerca de lo que le había ocurrido durante la semana. A esta pretensión de veracidad se debe el hecho de que todos los actores de las primeras temporadas mantuvieran sus nombres (y ocupaciones, pues ninguno era actor profesional) verdaderos dentro de la serie.

Sin embargo, a diferencia de la mayoría de los videoblogs que se encuentran en internet, Borja Pérez no se limitaba a grabarse a sí mismo hablando frente a la cámara, sino que intercalaba su relato con imágenes que nos mostraban algunos pasajes de lo que nos iba contando. Es decir, se pretendía convencernos de que, en su intención de contarnos lo que le sucedió durante la semana, Borja ocultaba cámaras en su casa para poder filmarse con Joseba o Nuria y luego incluía esas imágenes en su relato dominical. A este respecto, dice Ontiveros: «La verdad es que en unos primeros episodios sí me plantee la idea de que todo pareciera que lo grababa con cámara oculta Borja... pero la verdad es que no tenía mucho sentido, y creo que quedaba confuso» (Ionlitio, 2011).

La intención de hacer pasar por real el videoblog duró muy poco y, tras abandonar la pretensión de veracidad y asumirse abiertamente como una serie de ficción, QVMT ganó mucho en libertad creativa, los guiones se hicieron más arriesgados, se introdujeron más personajes y se complicaron las tramas. La estructura del videoblog, no obstante, se 
mantuvo; es decir, a lo largo de los cinco años que duró la serie, todos los capítulos empezaron igual, con Borja sentado sobre su cama contándole a una cámara fija lo que le había sucedido en la última semana; esta narración iba acompañada de imágenes que nos mostraban lo que Borja iba narrando o comentando.

Si bien la serie hizo su ingreso a la televisión sin hacer mayores cambios a nivel formal, con el paso del tiempo fue claro que perdió algo de la frescura que la caracterizó en internet (algo que mencionan los propios protagonistas en el capítulo «Internet era mejor») y terminó convirtiéndose en una especie de comedia de situaciones, con cameos de famosos, parodias de películas y un happy end en el último capítulo de la serie.

QVMT llegó a su final, quizás, debido precisamente a que la serie se terminó convirtiendo en una comedia de situaciones: el canal de televisión La Sexta transmitía los capítulos sin respetar ningún orden, intercalando indistintamente capítulos pasados con nuevos; esto hizo que el hilo narrativo se rompa y los personajes terminen estancados. La serie se volvió repetitiva y se quedó sin muchas posibilidades de sobrevivir en la televisión.

Esta serie resulta particularmente interesante por la evolución que experimentó a lo largo de sus cinco años y por la manera en que esa evolución tuvo un impacto en los cambios que sufre la personalidad del protagonista: Borja Pérez. Por ello, el presente texto parte de la hipótesis de que la serie muestra el padecimiento, la rebeldía y la caída del protagonista frente al cinismo, que lo va aprisionando hasta oprimirlo completamente y terminar acogiéndolo en su seno. No obstante, esta opresión solo puede darse si el sujeto renuncia a su deseo, a lo más verdadero que hay en él. El título de la serie, entonces, puede leerse como una alusión a lo lamentable que resulta renunciar al deseo propio y convertirse en un sujeto cínico: iqué vida más triste es la que está condenada al cinismo! Sin embargo, la serie plantea también una salida al cinismo: el amor.

Recordemos que, originalmente, el cinismo fue una escuela filosófica que predicaba la independencia del hombre frente al riesgo de la alienación intrínseca a la sociedad. Se justificaba, por lo tanto, violar 
algunas reglas y normas sociales con el fin de evitar dicha alienación. Sin embargo, en la actualidad, la Real Academia de la Lengua, en su edición electrónica, define cinismo como «desvergüenza en el mentir o en la defensa y práctica de acciones o doctrinas vituperables». Esta definición, en tanto no hace alusión alguna a los fines que pudieran estar detrás de estas acciones o doctrinas «vituperables», se acerca a lo que se conoce como el cinismo contemporáneo o posmoderno. Para poder establecer de manera más clara la distinción entre el cinismo antiguo y el posmoderno, podemos apelar a la descripción que hace Slavoj Žižek del «héroe»y del «canalla»:

el canalla es inmoral (viola las normas morales) y no ético (no persigue el deseo sino los placeres y los beneficios, y por eso carece de todo principio firme) $[\ldots]$ el héroe es inmoral, pero ético, es decir, viola (o más bien, suspende la validez de) las normas morales explícitas existentes en nombre de una ética superior de la vida, la Necesidad histórica, por ejemplo (2003:108)

Entonces, si aplicamos estas categorías a los dos tipos de cinismos, tenemos que el antiguo cinismo encaja en lo que Žižek calificaría como «heroico», en la medida en que todavía se cree en algún tipo de fin último al que vale la pena aspirar. Por otro lado, el cínico posmoderno, en tanto ha perdido la fe en cualquier tipo de fin último o ideal y se ha entregado al mandato de gozar más allá de cualquier norma moral, es un canalla. Esta persecución de un goce ilimitado y constante es una quimera, e implica renunciar a entablar vínculos verdaderos con los otros y con el propio deseo.

Borja Pérez, protagonista de la serie QVMT, encaja perfectamente en esta defición; es un sujeto que persigue su propio goce y, en la búsqueda de este, se va quedando solo.

\section{Metodología}

Para iniciar el análisis de QVMT, este texto se centra en la evolución de la personalidad del protagonista a lo largo de las siete temporadas que 
tuvo la serie durante los cinco años que duró. Es en esa evolución en donde se ve cómo la serie muestra a Borja Pérez empezar rebelde ante la hipocresía y el cinismo que lo rodea para luego mostrarnos su resignado sometimiento, que es presentado como la consecuencia lógica de la inutilidad de su lucha inicial y su posterior derrota. Finalmente, se aborda el aislamiento en el que vive Borja Pérez. Aislamiento que es consecuencia directa de su cinismo, que le impide crear vínculos duraderos o profundos con la gente que lo rodea, en especial con Nuria, su novia. Su entrega al cinismo hace que sea incapaz de ver en el encuentro amoroso un acontecimiento que le permita reconstituir su subjetividad para poder huir del cinismo que lo aprisiona. También, se muestra cómo el deseo puede proteger al protagonista del goce que encuentra en el cinismo.

\section{Análisis}

Como ya se señaló, el personaje protagonista de la serie se llama Borja Pérez, maneja una grúa en una empresa constructora, vive con sus padres y, cada domingo, en su habitación, se sienta frente a su cámara y narra en breves minutos lo más resaltante que le ha sucedido durante la semana. Por otro lado, el actor que hace el papel de Borja Pérez en la serie, también se llama Borja Pérez, no es un actor profesional, sino que trabaja manejando una grúa en una empresa constructora, vive con sus padres y, según ha dicho Rubén Ontiveros, la serie se graba siempre en su habitación (Ionlitio, 2011). Tal como se planteó en la introducción, el hecho de que actor y personaje compartan la misma biografía es producto del deseo del creador de la serie de hacer pasar QVMT por un videoblog verídico. Sin embargo, las semejanzas entre realidad y ficción se prestan, primero, al juego de borrar los límites entre ellas y, después, al de plantear dos mundos dentro de la serie: el mundo «ficticio» del Borja personaje y el mundo «real» del Borja actor.

Este juego se va consolidando durante la primera temporada y, al iniciarse la segunda, se nos plantea una clara división entre el mundo ficcional y el mundo real. La separación entre el mundo ficticio del que llamo «Borja personaje» y el mundo real del que llamo «Borja 
actor» será bastante evidente en los diálogos entre estos. Por un lado, vemos al primero inmerso en su trabajo como operador de una grúa, a sus amigos y a su novia; por otro lado, vemos, en algunos capítulos, al Borja actor mientras planea los episodios en los que representará al Borja personaje, comenta el guión con Rubén Ontiveros e, incluso, discute con este la pertinencia de alguna frase o comentario. Sin embargo, la presencia de Borja actor es muy escasa (podríamos decir, incluso, excepcional), pues aparece muy brevemente y solo al inicio de algunos capítulos. Entonces, para el inicio de la segunda temporada tenemos dos entidades bien diferenciadas: el Borja actor, por un lado, y el Borja personaje, por el otro. El primero estaría fuera de la ficción y el otro, dentro. El papel de este último es, entonces, romper con la construcción ficcional, interrumpir el discurso y reflexionar sobre él; de ahí que esta distinción nos lleve a juegos «metatextuales».

QVMT se vale de estos juegos metatextuales para mostrarnos lo inútil que resulta luchar contra el cinismo. Esto lo podemos ver en los diálogos del protagonista y su novia Nuria durante el cuarto capítulo de la primera temporada, por ejemplo. Este episodio se inicia con Borja quien cuenta, sin ocultar su satisfacción, que la noche anterior estuvo en una fiesta llena de excesos: «QQué fiesta!... borrachera... vomitando... perdí el móvil, arrastrándome por el suelo, me pisaron en la discoteca... ¿Qué fiesta!... y que mal estoy ahora con la cabeza, no la siento, iQué resaca!». Luego de darnos algunos detalles más, se pregunta qué hacer. Tras una breve reflexión, decide llamar a Nuria, pues «para eso están los domingos, para eso están las novias»; evidentemente, ella no estuvo en la fiesta.

Cuando llega a la casa de Borja, este la invita a ver una película de acción de Steven Segal; ante la negativa de Nuria a verla, Borja le propone ir directamente al sexo. Nuria, enfurecida, se va y deja a Borja solo en su cuarto. Luego, él nos dice, resignado, que va a tener que leer un poco y después irse a dormir. Los diálogos de este capítulo son muy útiles para empezar a delinear la personalidad del personaje de la serie, no solo en relación a su condición de sujeto desprotegido frente al imperativo del goce, sino también frente a un empuje narcisista: Borja 
en ningún momento muestra interés alguno por el otro, pretende usar a Nuria como si fuese un objeto y podríamos decir, incluso, que entre Borja y Nuria no hay, propiamente, una relación, pues solo ve en ella un medio para satisfacer sus deseos egoístas. Pero podríamos dar un paso más y decir que Borja no es un cínico cualquiera, sino que es un canalla:

El cínico es el que niega la existencia del gran Otro, el que no cree en el deber-ser colectivo ni en la posibilidad o en la necesidad de su vigencia. El canalla, por su parte, es una especie entre la familia de los cínicos que finge la identificación con el ideal para hacer prosperar sus propios intereses. (Ubilluz, 2006: 41)

A través de los diálogos del undécimo capítulo de la primera temporada, vemos que Borja le pide a Nuria explicaciones y detalles de su infidelidad (de la que nos habíamos enterado en el capítulo anterior). Tras oír a Nuria, él le dice «Yo sé perdonar», pero inmediatamente vemos al Borja narrador, es decir, al que nos va contando todo, sentado, decir desde su cama: «iPerdonar ni una mierda! iAquí va a haber sexo oral todos los días!». Luego volvemos a la escena en que están Borja y Nuria conversando, él le dice que la perdona pero aun así ella no acepta volver con él. «Esto no va a funcionar», le anuncia ella y se levanta para retirarse; Borja la toma del brazo y le dice: «Y un último de despedida ¿o algo?». Evidentemente, se refiere a una última relación sexual, lo cual enfurece a Nuria, quien se marcha gritándole.

Este capítulo me permite plantear dos puntos: el primero es que Borja es un canalla, en el sentido planteado tanto por Žižek como por Ubilluz, pues miente, manipula, finge ser un sujeto noble para luego poder chantajear sentimentalmente a su novia, y todo para obtener un goce narcisista que no ve en el otro más que un medio. El segundo punto que los diálogos de este capítulo permiten visibilizar es la contradicción entre el «hacer»y el «decir». Si habíamos hecho una división entre el Borja actor y el Borja personaje, ahora debemos dividir a este último en dos: el «Borja narrador» y el «Borja protagonista». Es decir, entre el Borja que, los domingos, sentado en su cama, nos cuenta las cosas que le han sucedido durante la semana y el Borja al que vemos participando 
activamente en los hechos que se nos narran. Muchas veces, mientras el Borja narrador nos dice una cosa, vemos al Borja protagonista haciendo otra. Esto es algo que vemos a lo largo de toda la serie y que se va acentuando hacia las temporadas finales. Observamos capítulos en los que el Borja narrador se presenta como un sujeto digno y honesto, para luego ver al Borja protagonista, quien hace todo lo contrario de lo que se nos dijo, o viceversa: vemos al Borja protagonista actuando de manera correcta y honesta (siempre obligado por las circunstancias) y luego al Borja narrador, quien se burla de sí mismo o insulta a quienes lo llevaron a actuar de esa manera y da a entender que su intención, oculta tras su aparente honestidad, era otra.

En el vigésimo capítulo de la primera temporada, por ejemplo, vemos al Borja protagonista observando una película con Laura, la joven con la que ha empezado a salir para intentar olvidar a Nuria, pero a mitad de la película recibe una llamada y Borja tiene un breve diálogo con Nuria, en el que ella lo invita a reunirse y él acepta inmediatamente. El Borja narrador señala que aunque Laura no ha escuchado su conversación, va a querer preguntarle con quién ha hablado, y dice: «Laura es muy lista y va a querer pillarme, pero a mí no me pilla nadie, ni Dios... antes que me pille, yo con la verdad por delante, se lo cuento». Inmediatamente después, vemos al Borja protagonista contándole a Laura que era Joseba quien lo llamó para devolverle un videojuego de la play station. Esta mentira acarrea otras más y al final del capítulo queda al descubierto ante Laura. Propongo entender esta división del Borja personaje a partir de lo que plantea Gonzalo Portocarrero acerca del cínico:

La figura del cínico es contemporánea, corresponde a una sociedad individualista y secularizada en la que el mandato a pasarlo bien es el más prominente. Pero lo contemporáneo no excluye al pasado sino que se enraíza en él. La organización de la subjetividad es un fenómeno que tiene que ser pensado desde la larga duración. Es decir, es casi imposible evadir los ideales de ihaz el bien! y itrabaja! El primero propio del cristianismo, y seguro de todas las religiones; el segundo característico de la tradición protestante. (2010: 250) 
Entonces, la escisión entre el «hacer» y el «decir» sería este fluctuar entre dos mandatos que atormentan a Borja y que lo llevan a mentirnos a nosotros, los espectadores de su videoblog, a pesar de que sabe que su mentira no tiene ningún sentido, pues, inmediatamente después de oírla, veremos lo que realmente sucedió. Esta es la razón por la que considero que el Borja narrador no es un sujeto canalla, pues si un canalla es alguien que finge la identificación con el ideal para obtener algún beneficio, ¿qué beneficio podría obtener Borja de elaborar una mentira cuyo efecto solo durará unos pocos segundos antes de quedar al descubierto? Antes de continuar, dejémoslo claro: el Borja protagonista miente porque es un sujeto canalla que se valdrá de cualquier argucia para conseguir su beneficio narcisista.

Por otro lado, el Borja narrador miente porque se encuentra atormentado entre dos mandatos y no sabe exactamente qué es lo que quieren los otros de él. En este caso, nosotros. ¿Queremos verlo gozando en una fiesta hasta terminar arrastrándose en el suelo de una discoteca, o preferimos verlo digno y que se presente como un sujeto honesto? No obstante, debemos subrayar que este fluctuar entre dos mandatos se queda solo en el «decir», jamás en el «hacer». El Borja protagonista actúa siempre como el cínico canalla que es, jamás hace algo que no busque su propio beneficio. Sin duda, esto sucede porque, al relatarnos lo que le ha sucedido, el Borja narrador se distancia de sí mismo (del Borja protagonista) y, al hacerlo, se observa y evalúa, lo que lo lleva a tener un conflicto interior. Sloterdijk acierta cuando dice: «Los cínicos no son tontos y más de una vez se dan cuenta, total y absolutamente, de la nada a la que todo conduce» (2003: 40).

Estos juegos que llamo «metatextuales» nos permiten analizar la figura de Borja Pérez (actor, narrador, protagonista) para formarnos una imagen más compleja del sujeto cínico. Los cambios que va sufriendo la serie a lo largo de las temporadas son muy interesantes a este respecto. Sin embargo, si hay algo en lo que el protagonista de la serie se mantiene constante a lo largo de todas las temporadas en internet y en televisión, es en su amor hacia Nuria. Lo vemos pelear con ella, reconciliarse, volver a pelear, amistarse y estar a punto de casarse. 
Pero Borja le es infiel y vuelven a pelear, aparentemente, de manera definitiva, por lo que Nuria reduce drásticamente sus apariciones en la serie en buena parte de las temporadas finales, solo para reaparecer en los últimos capítulos de la última temporada y reconciliarse con Borja en el episodio final.

El tema del amor es central en la serie, el protagonista se ve interpelado una y otra vez por este sentimiento, pero su cinismo le impide encontrar en él un verdadero acontecimiento que transforme su subjetividad. El amor, para Borja Pérez, es un simulacro que se confunde con el placer que le produce el sexo narcisista. Borja, en tanto sujeto cínico, se resiste a ver, en ese sentimiento que lo interpela, algo verdadero, por lo que lo evita con su cinismo. Al final, sin embargo, no puede seguir ignorándolo. La pregunta que se impone aquí, y que no he abordado más que tangencialmente, es la de por qué razón Borja elige siempre el cinismo. La respuesta, sin duda, es el goce que este le proporciona:

La razón por la cual nos resulta imposible librarnos de un síntoma que experimentamos conscientemente como algo doloroso y perturbador, estriba en que en otro nivel obtenemos de él cierto beneficio (primario o secundario), cierto goce (como algo opuesto al placer consciente) (Stavrakakis, 2010: 100)

Desde una perspectiva psiconanalítica, el goce es opuesto al placer en tanto este último «implica un reconocimiento mutuo, la reciprocidad entre dos conciencias», mientras que el goce "es la sustancia vital que se 'retuerce' en su insatisfacción, que pugna por realizarse, sin tomar en cuenta al otro y la ley» (Portocarrero, 2007: 1). Entonces, podemos decir que Borja, al entregarse al cinismo, experimenta un goce que, inconscientemente, lo embelesa y seduce. En este sentido, Borja es un sujeto que se niega a aceptar la castración:

La oposición entre goce y castración es fundamental puesto que esta oposición es el eje sobre el que se articula la dirección de la cura [psicoanalítica]. El sujeto debe renunciar al goce a cambio de una promesa de otro goce que es propio de los sujetos de la ley (Portocarrero, 2007: 1) 
Y ¿́cuál es este goce que es propio de los sujetos de la ley? La respuesta nos la da el mismo autor: «El amor es el sentimiento encargado de suplir la inexistencia de la relación sexual y de reaportar el goce al que se debió renunciar» (2007: 1). Es por esta razón que la relación entre Borja y Nuria es tan importante, pues representa la posibilidad de defender a Borja del goce que le proporciona el cinismo. Alain Badiou sostiene que el amor es un acontecimiento que activa un proceso de verdad. Se entiende «acontecimiento" como un "plus» que sobreviene en las situaciones como «un suplemento azaroso, imprevisible, que se disipa apenas aparece» (Badious, 2004: 100) que se encuentra más allá de lo conocido, lo esperable, los saberes instituidos y que hace advenir «otra cosa». Este acontecimiento nos enfrenta al vacío de una situación, y, ante este, Badiou plantea la fidelidad a ese acontecimiento, fidelidad que consiste en pensar la situación «bajo el imperativo del acontecimiento mismo» (2004: 100). Esta fidelidad produciría la verdad y al sujeto:

Se llama 'verdad' (una verdad) al proceso real de una fidelidad a un acontecimiento. Aquello que esta fidelidad produce en la situación. [...] Se llama 'sujeto' al sostén de una fidelidad; luego entonces, al sostén de un proceso de verdad. El sujeto no preexiste para nada al proceso. Es absolutamente inexistente en la situación 'antes' del acontecimiento. Se dirá que el proceso de verdad induce un sujeto. (Badiou, 2004: 72-73)

Sin embargo, cuando un hecho no nos confronta con el vacío ni lo inesperado, sino con la plenitud y lo esperable, entonces no estamos frente a un acontecimiento, sino frente a un simulacro:

Cuando con nombres tomados en préstamo a los procesos reales de verdad, una ruptura radical en una situación convoca, en vez del vacío, la particularidad «plena» o la sustancia supuesta de esta situación, diremos que se tiene un simulacro de verdad. (Ibid. 107)

Badiou reconoce cuatro tipos de procesos de verdad: político, científico, artístico y amoroso (2004: 55). Evidentemente, el proceso de verdad al que Borja Pérez se encuentra más cercano es al amoroso, pues no tiene una especial sensibilidad artística y su cinismo le impide 
comprometerse con cualquier propuesta política. Debido a ello, el amor lo interpela más de una vez, lo confronta con el vacío de la situación, pero él siempre huirá de él aferrándose al simulacro, a la seguridad que le da el cinismo y el guión que este le elabora, a través de la pornografía, para asumir su relación con el otro. Es por esta razón que, con respecto al amor, Borja Pérez está condenado a fracasar en sus intentos de establecer vínculos verdaderos con los otros. Esta premisa queda muy clara en el capítulo 37 de la cuarta temporada, «Media naranja». En este episodio, Borja conoce por casualidad a una mujer que es idéntica a él: trabaja en una grúa, le gusta la pornografía, le encantan los juegos de video y hasta tiene las mismas expresiones que Borja. «Pero si es perfecta para ti, Borja, que es tu media naranja», le dice Joseba. Pero Joseba se equivoca, la mujer que acaba de conocer Borja es idéntica a él y, por eso precisamente, jamás podría haber una verdadera relación entre ellos, pues ella es igual de cínica que él. A pesar de creer que la chica que acaba de conocer es su media naranja, Borja la engaña y, para ocultar las marcas que la infidelidad le dejó en el cuello, se pone una chompa de cuello alto, lo que no pasa desapercibido para Joseba, pues están en pleno verano. Con una mentira preparada, Borja va a visitar a su «media naranja». Ella lo recibe con una chompa igual a la de él y una mentira para justificarla. No hace falta decir más, ambos se despiden y, antes de que Borja se retire, ella le pide que no la llame más. Queda claro, entonces, que el sujeto cínico es también un sujeto elitista y excluyente, en la medida en que necesita de sujetos que no sean como él para que la relación narcisista que busca pueda funcionar.

Borja encuentra este tipo de relación con Nuria, luego con Laura y Cristina, las dos novias que tiene tras ser abandonado por la primera. Sin embargo, y precisamente por tratarse de mujeres que no se han entregado al cinismo como Borja, las relaciones que establecen con él no pueden durar, pues llega un momento en que se cansan de ser manipuladas y engañadas por él, que jamás se compromete realmente con alguna de ellas. El sujeto cínico está condenado a la soledad de las relaciones instrumentales, y esta soledad se manifiesta en la predilección que Borja tiene hacia la pornografía. En tanto sujeto desprotegido frente al mandato al goce, Borja tiene a la pornografía como la fantasía que 
sostiene su relación con Nuria. Esto queda muy claro en los diálogos del cuarto capítulo de la tercera temporada.

En este episodio, Borja nos cuenta que, hace dos años, Nuria descubrió una película porno en su habitación, ante la evidencia, él no lo negó y lo aceptó, pero ella se molestó tanto que lo dejó todo un mes sin tener relaciones sexuales. «El hombre es el único animal que tropieza dos veces con la misma piedra", dice Borja antes de contarnos que Nuria volvió a encontrar una película pornográfica en su habitación, pero, esta vez, él lo negó todo e inventó la historia de que se trataba de un video sorpresa por su aniversario. Luego, la convenció de que vuelva en la tarde para que vean el video los dos juntos. Una vez que Nuria se ha ido, Borja consigue la ayuda de Joseba e improvisa un video en el que le declara su amor a Nuria e intercala algunas imágenes con muestras de su cariño, todo esto es grabado sobre la cinta porno que Nuria había encontrado en el cuarto de Borja. Cuando, luego de ver el video, Nuria se lo agradece con un abrazo, el video grabado por Borja termina y la grabación original (la película porno) aparece en la pantalla.

Considero que en este episodio queda clara la fantasía que sostiene las relaciones que establece Borja con Nuria. Si recordamos lo que nos dice Slavoj Žižek acerca de que «el inconsciente está expuesto, no oculto por una profundidad insondable; o, citando el lema de Los expedientes secretos X: "La verdad está afuera"» (1999: 11), podemos leer este episodio como una muestra de la verdad de la fantasía que estructura las relaciones del sujeto: en su relación con Nuria, el amor romántico, como el que expresa en el video grabado para ella, es solo la pantalla que oculta sus verdaderas intenciones, el sexo. Sin embargo, y tal como se vio anteriormente, el protagonista se debate entre la entrega al cinismo y la fidelidad a sus sentimientos hacia Nuria, que no puede ignorar. En el episodio 11 de la cuarta temporada, «Sitcom», por ejemplo, Borja descubre que está viviendo en una especie de comedia «enlatada», pues cada vez que hace un chiste, se oyen risas grabadas, así como también se oyen aplausos cuando ingresa algún personaje en el episodio. «iA lo risas enlatadas!», dice cuando lo descubre. Borja disfruta de esta situación durante un tiempo, hasta que su padre le comunica que Nuria 
irá a buscarlo ese día en la tarde. En ese momento, se pone serio, se propone reconquistarla y llegar a ella siendo sincero. Pero cuando habla con Nuria y es sincero, se oyen las risas enlatadas. Borja no comprende el porqué, pues no está tratando de ser gracioso, al contrario, está hablando en serio, está siendo sincero con Nuria porque realmente quiere volver con ella: «Eres la persona que más quiero en este mundo», le dice, e inmediatamente se oyen risas; "no hay cosa que me duela más en este mundo que lo hayamos dejado tú y yo», agrega y las risas se oyen más fuerte. Nuria piensa que todo se trata de una broma y se va furiosa, dejando a Borja solo y desconcertado.

Llegado a este punto, Borja personaje pareciera ya no poder salir del cinismo. De hecho, el capítulo continúa con Borja quejándose de las risas enlatadas y pidiendo que paren, pero las risas se vuelven a escuchar, como si su molestia no fuera en serio. Finalmente, el capítulo termina con una clásica melodía de dibujos animados mientras Borja mira a la cámara, sorprendido. En tanto estamos ante uno de los primeros capítulos de la primera temporada de la serie en televisión, podríamos entender la actitud de perplejidad de Borja ante su situación, pues el paso de internet a la televisión implicó el abandono de toda pretención de realismo en la serie para convertirse en una típica comedia de situaciones, sin mucha relación de secuencialidad entre cada uno de los capítulos. En este sentido, Borja pareciera mostrar su sorpresa ante el giro que ha tenido su situación, pero esta sorpresa dura muy poco, ya que después se entrega al cinismo sin mayor problema.

Sin embargo, Borja se entrega al cinismo en sus relaciones con los otros consciente de que lo que siente por Nuria es algo más que una pura atracción sexual, él sabe que el amor es más importante para su vida de lo que le gustaría aceptar, y esto es algo que puede verse especialmente en los diálogos del tercer capítulo de la quinta temporada, «El gran juego de tu vida». En este episodio, Borja es seleccionado por un nuevo programa de concursos en la televisión. «De preguntas y respuestas, de cultura general», dice. No obstante, una vez en el set de televisión, las preguntas que le plantea la conductora poco tienen que ver con cultura general y mucho con la vida privada de Borja. Le pregunta, por ejemplo, si es cierto 
que inventó una deficiencia mental de Joseba para conseguir una ayuda financiera, o si es cierto que le robó a su padre el dinero que este había juntado para operarse de la rodilla. Borja contesta estas y otras preguntas afirmativamente sin hacerse ningún problema; incluso, luego de responder, saluda a su padre y amigos que se encuentran entre el público asistente al programa. A pesar de estar presentándose como un sujeto manipulador y mentiroso frente a los televidentes, a su padre y amigos, Borja no parece inmutarse y, al contrario, conforme va avanzando en el concurso y va acumulando dinero por cada pregunta bien contestada, su emoción aumenta.

Finalmente, para que pueda llevarse el premio mayor, la conductora le hace la última pregunta: «¿Sigues enamorado de Nuria, tu ex?». «No voy a seguir colaborando con esta telebasura, vergüenza os tendría que dar hacer este tipo de preguntas», contesta y se retira del concurso. Al negarse a responder, Borja no solo pierde todo el dinero acumulado hasta ese momento, sino que deja en evidencia que para él, un cínico, estar enamorado es un problema, es algo que hay que tratar de ocultar ante los demás, para Borja Pérez el amor es algo vergonzoso, de lo que hay que huir. Por esta razón, siente tanta rabia hacia Joseba cuando este decide casarse, pues Joseba sí tuvo el valor de hacer lo que él no pudo: asumir la responsabilidad del encuentro amoroso y entregarse a él, con todo lo que esto implique para él y su pareja. Esta rabia puede verse en los diálogos del capítulo 39 de la segunda temporada. En este episodio, Joseba se casa con Izaskun, su novia, y, en medio de la fiesta, Joseba trata de explicar a Borja que debe aceptar a Izaskun, pues él es su mejor amigo y ella, su mujer. Borja responde afirmativamente, lo abraza y le dice que si ella lo hace feliz, pues no importa nada más. Sin embargo, Borja aprovecha un pequeño vahído de Joseba para pintar en su camisa «Izaskun zorra» y, luego, cuando Joseba le quiere dedicar una canción a Izaskun, Borja cambia la pista y hace que suene una canción bastante ofensiva para ella.

Más adelante, en el noveno capítulo de la sexta temporada, «Infidelidades», Borja intenta convencer a Joseba de que le sea infiel a Izaskun apelando a argumentos delirantes, pues una mujer se ha ofrecido a tener una noche de sexo con Joseba, pero él la ha rechazado por estar 
casado, algo que Borja no entiende. Todas estas actitudes de Borja hacia Joseba nos recuerdan lo que dice Juan Carlos Ubilluz:

como todo aquel que ha cedido en su deseo, [el sujeto] se ve obligado a condenar a quien no ha cedido en el suyo. Después de todo, no es tan fácil renunciar a lo "más preciado" que hay en uno. O mejor aún, uno puede renunciar al deseo, pero el deseo no renuncia a uno, y desde lo real, insiste en hacerse reconocer (2009: 156).

Este real que insiste en hacerse reconocer no deja en paz a Borja a lo largo de toda la serie y se dedica a una frenética labor para combatir su deseo. Algo que queda en evidencia en los últimos capítulos de la serie, cuando Borja intenta seducir a Sara, su vecina lesbiana. Si bien estamos acostumbrados a sus continuos asedios a las mujeres que lo rodean, el caso de Sara es más patético, pues Borja está convencido de que puede hacer que Sara deje de ser lesbiana para estar con él.

En el episodio 28 de la última temporada, ella le pide que finja ser su pareja para ocultarle al padre de ella su homosexualidad. Borja intenta aprovechar la situación y monta una farsa para engañar a Sara y poder casarse con ella. Sin embargo, a diferencia de todas las ocasiones en las que, a lo largo de la serie, se valió de trucos, mentiras y engaños para poder estar con alguna mujer, en esta ocasión hay algo que lo detiene. Cuando está a punto de besar a Sara para dar por finalizada la ceremonia y casarse con ella, Borja no lo hace, no la besa. Sara le pregunta sorprendida qué sucede y Borja, sorprendido también, le dice «no puedo» y repite, pero esta vez como si se lo dijera a sí mismo: «No puedo». Si se tiene en cuenta la evolución del personaje, este gesto es bastante singular. Lo habíamos visto fracasar muchas veces intentando conquistar mujeres, pero el fracaso siempre era resultado de alguna circunstancia ajena a él. Esta es la primera vez en que su plan parece funcionar, todo va saliendo como él lo esperaba, pero entonces él se arrepiente, su gesto de sorpresa pareciera anunciar un verdadero cambio en él: una verdadera voluntad de ser fiel a su deseo y entregarse al acontecimiento amoroso que, con un poco de esfuerzo, lograría 
ayudarlo a atravesar la fantasía cínica que sostiene su forma de ver las cosas y conducirlo a reconstruir su subjetividad:

Está claro que bajo el efecto de un encuentro amoroso, y si quiero serle fiel realmente, debo recomponer de arriba abajo mi manera ordinaria de 'habitar' mi situación (Badiou, 2004: 71).

\section{Conclusiones}

La serie española Qué vida más triste nos cuenta la historia de un sujeto condenado a vivir en el cinismo. Se ha intentado visibilizar la evolución que ha sufrido la serie y, junto con ella, el protagonista, a lo largo de sus siete temporadas. Esta evolución ha permitido plantear que la serie muestra la complejidad de la personalidad del sujeto cínico. El cinismo, en tanto discurso que hegemoniza la cultura, es un mandato que se impone y que va apoderándose del sujeto que intenta, sin mucho éxito, resistirse a él.

El análisis de los diálogos y el lenguaje corporal del protagonista, nos ha permitido mostrar cómo el cinismo condena al protagonista al aislamiento y le evita la posibilidad de un encuentro enriquecedor con el otro. Las relaciones que entabla el sujeto cínico se basan en el narcisismo y, por esta razón, lo encierran en sí mismo y no le permiten escapar del goce que lo encapsula en un comportamiento autodestructivo. Frente a esto, se planteó la posibilidad del amor como iniciador de un proceso de verdad que reconstituya por completo al sujeto y le permita encontrar algo del goce perdido que le prometía el cinismo, pero enmarcado dentro de un universo simbólico regido por la ley.

El interés por la serie radica en que QVMT visibiliza la hegemonía del cinismo en la época contemporánea, pero también muestra las posibilidades del sujeto frente a este. Estas posibilidades van desde una resistencia impotente hasta la entrega gozosa, y, desde luego, la posibilidad de escapar de él mediante la fidelidad a un proceso de verdad que enfrenta al protagonista al vacío de la situación. 
https://doi.org/10.46744/bapl.201901.003

\section{BIBLIOGRAFÍA}

BADIOU, Alain. (2004). La ética. Ensayo sobre la conciencia del mal. México: Herder.

IONLITIO. (2011). Quevidamastriste. Recuperado de http://www. ionlitio.com/quevidamastriste

. (2011) Entrevista a Rubén Ontiveros, director de 'Quevidamastriste'. Recuperado de http://www.ionlitio.com/ entrevista-a-ruben-ontiveros-director-dequevidamastriste.

PORTOCARRERO, G. (2010). Oído en el silencio, ensayos de crítica cultural. Lima: Red para el desarrollo de las ciencias sociales.

. (2007). El goce como concepto eje del psicoanálisis. Recuperado de http://gonzaloportocarrero.blogsome. com/2007/06/02/el-goce-como-conceptoeje-del-psicoanalisis.

QUIROGA, M. (2011). Entrevista a Rubén Ontiveros, creador de Qué vida más triste. Recuperado de http://www.vayatele.com/ ficcion-nacional/entrevista-a-ruben-ontiveros-cocreadorde-que-vida-mas-triste.

SLOTERDIJK, P. (2003). Crítica de la razón cínica. Madrid: Siruela.

STAVRAKAKIS, Y. (2010). La izquierda lacaniana. Psicoanálisis, teoría, política. Buenos Aires: Fondo de Cultura Económica.

UBILlUZ, J. (2006) Nuevos súbditos. Cinismo y perversión en la sociedad contemporánea. Lima: IEP.

. (2009). En el Nombre-del-Padre: Los cuentos morales de Luis Nieto Degregori. En Contra el sueño de los justos. Lima: IEP. 
LA (IN)TRASCENDENCIA DEL AMOR: UN ANÁLISIS DE LA TELESERIE QUÉ VIDA MÁS TRISTE https://doi.org/10.46744/bapl.201901.003

ŽIŽEK, S. (1989). El sublime objeto de la ideología. México: Siglo Veintiuno. . (1994). iGoza tu síntoma! Buenos Aires: Nueva Visión. . (1999). El acoso de las fantasías. México: Siglo Veintiuno. . (2006). Arriesgar lo imposible. Conversaciones con Glyn Daly. Madrid: Trotta.

. (2003). La metástasis del goce. México: Siglo Veintiuno. . (2008). En defensa de la intolerancia. Madrid, Sequitur. 